\title{
Cold Seeps Associated with Structured Benthic Communities: More Accurate Identification and Evaluation Using a New Multibeam Survey Methodology in the Offshore Southern Colombian Caribbean
}

\author{
Adrian Digby1, Vladimir Puentes ${ }^{2}$, Jorge León ${ }^{3}$ \\ ${ }^{1}$ Lionel Fray Associates, Katy, Texas, USA \\ ${ }^{2}$ Aquabiosfera \& Anadarko PC Inc., Woodlands, Texas, USA \\ ${ }^{3}$ Anadarko Colombia, Bogota, Colombia \\ Email: digby@borehole-geophysics.com
}

Received 16 April 2016; accepted 23 May 2016; published 27 May 2016

Copyright (C) 2016 by authors and Scientific Research Publishing Inc.

This work is licensed under the Creative Commons Attribution International License (CC BY). http://creativecommons.org/licenses/by/4.0/

\section{(c) (i) Open Access}

\begin{abstract}
A new methodology was developed to identify cold seeps and structured benthic communities associated, which was applied for the first time in the offshore southern Colombian Caribbean. The integral method consists on a new processing of double-coverage (200\%) high-resolution backscatter data combined with bathymetric information; validation was done correlating identified gas plumes, seabed cores and drift camera surveys. Results showed that the elimination of artefacts and the increased signal of the backscatter data allowed accurate plotting of seep boundaries and categorization of seeps into an activity catalogue, with more than 200 seeps identified. Most seeps have chemosynthetic communities associated and data analysis from a previous survey showed two ridges with hard ground as the only possible areas for the development the of deepwater corals. Seep results were compared with designated Areas of Significance for Biodiversity (ASB) identifying seeps both within and outside the ASBs, and showing that the presence of seeps and chemosynthetic communities associated were driven more by geological processes than for big-scale seabed morphology, since they were found in both plains and ridges. This methodology allows an accurate seabed map of structured benthic communities, which may work as a precise geo-hazard map to ensure the oil \& gas industry can avoid these areas of shallow gas for further developments, and as a map of deep-water structured benthic communities with environmental significance.
\end{abstract}


Keywords

\section{Backscatter, Cold Seeps, Chemosynthetic Communities, Southern Colombian Caribbean}

\section{Introduction}

Colombia is promoting the offshore exploration in the Colombian Caribbean through the National Agency for Hydrocarbons (ANH) and several operating Oil \& Gas companies are becoming interested in doing studies in the region. Offshore exploration is done in several steps, such as seismic surveys, multibeam and piston coring surveys, analysis of information obtained and exploratory drilling. An environmental license (issued by the Environmental Licenses Agency_ANLA) and/or a maritime permit (issued by the maritime authority-DIMAR) is needed to carry out all these offshore exploration activities, depending on each case.

An environmental impact assessment (EIA) is required for some of the previous processes mentioned, and according to the terms of reference for EIAs, it is required to do baseline studies that characterize the area of interest. These studies include the identification of protected or environmentally sensitive areas, such as national natural parks in their different categories and the Areas of Significance for Biodiversity (ASB), first reported by Alonso et al. (2010). According to these studies ASBs can be found in the majority of offshore exploration blocks. Since these ASBs were defined based on regional studies and considering that their designation should prompt further research efforts to guide the adoption of management and conservation decisions, it was decided to study these areas in greater detail using a novel methodology, including an in-depth analysis of the ASBs in the offshore Gran Fuerte area (Southern Colombian Caribbean). During this process, cold seep identification has been a key tool for oil \& gas exploration, discovering new sites [1] in unexplored areas, since the first cold seep was discovered off Louisiana [2], and features such as formation of authigenic carbonate constructions and biological activity were reported around them [3]. These seeps may be surrounded by life, such as bivalves, vestimentiferan tube worms, ponogophorans, cladorhizid sponges, gastropods and shrimps, among others [4].

This study presents a new method based on multibeam high-resolution data and its validation, as part of the offshore exploration surveys that offers brand-new environmental information, which may be useful for both the oil \& gas industry and the environmental regulatory and conservation agencies in Colombia. This work was done in the frame of the offshore exploration activities of the Blocks URA 4, COL 5, Purple Angel, Fuerte Norte and Fuerte Sur (Gran Fuerte Area), in which Anadarko and Ecopetrol are equal partners in the contracts issued by the ANH.

\section{Methods}

In 2014 and 2015 a multibeam echo-sounder survey (MBES) was carried out with an echo-sounder KORNSBERG EM122 over a large area of the southern Caribbean waters, covering approximately 22,500 $\mathrm{km}^{2}$, which also incorporated data from a 2006 previous survey. Coring locations were identified and performed based on the MBES survey data for geochemical exploration, focusing on the Gran Fuerte area (Figure 1; $14.200 \mathrm{~km}^{2}$ ); drift camera surveys on strategic areas were carried out on the seabed to confirm the interpretation of the multibeam data. Although the survey covered a wide area, special attention was given to the various areas of the Gran Fuerte area designated as Areas of Significance for Biodiversity (Figure 1: ASBs framed green) reported by [5].

The dual need for accurate geochemistry and precise ecological mapping led to the use of a new method of multibeam surveying, with bathymetry and backscatter data being obtained at a greater resolvability in deep water than any previous extensive survey. The seabed coring survey followed and confirmed the accuracy of the interpretations. Although this method is valuable for a number of different purposes, this paper describes its use from an environmental perspective. The method and survey interpretation allowed remote mapping in detail of seabed morphology, leading to the identification of cold seeps and accurately identifying the presence or absence of structured benthic communities associated, both within and outside the ASBs in the Gran Fuerte area.

The MBES backscatter resolution data was mapped as pixels of $3 \times 3$ bin size, and bathymetry resolution was $15 \times 15 \mathrm{~m}$, which is the highest resolution normally available for a deep water survey at these depths (700 $2800 \mathrm{~m}$ ). Recent improvements to multibeam systems have occurred enhancing the density of the data both along line, using "double pinging”, which doubles the along-line resolution even at higher vessel speeds, and 


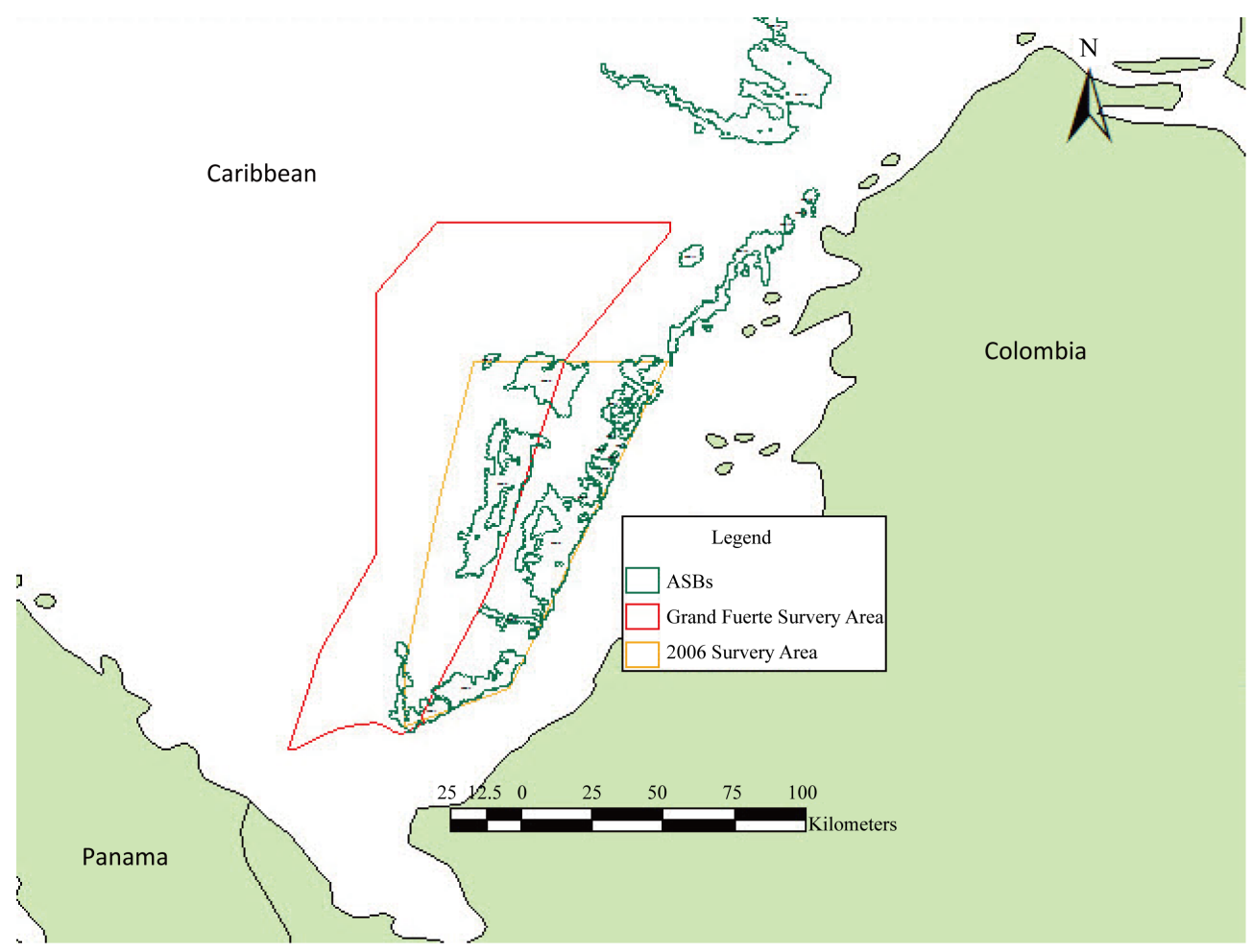

Figure 1. Gran Fuerte area in Southern Colombian Caribbean (red frame). Areas of significant biodiversity (based on Alonso et al., 2010, green frame), and 2006 survey area (yellow frame).

across line, by doubling the actual number of transceivers. These improvements made identification of seep related expulsion features with clear bathymetric signatures possible with a high degree of certainty. However, to increase the certainty that cold seeps could be identified accurately using the backscatter data, which is the most valuable data set, the MBES data was gathered over two passes, surveying the seabed at $200 \%$ coverage, and examining the same area twice but at a different angle (Figure 2), integrating the results with software including (Neptune $^{\circledR}$, Poseidon $^{\circledR}$, Caris ${ }^{\circledR}$ with FM Geocoder ${ }^{\circledR}$ ). The vessel completes a $100 \%$ coverage surveying along a set of primary lines and then a second pass along a secondary set of lines equally spaced between and parallel to the primary lines covers the same area twice, as shown in Figure 3.

Water column data from the MBES survey recorded water column reflections that were used to identify the location of gas plumes; these gas plumes were correlated with cold seeps in all cases. Finally, a sweep of the data was made to determine whether any areas of "hard ground" did exist that may allow the development of deep-water corals within the whole study area (Figure 1; Gran Fuerte and 2006 survey).

\section{Results}

The total Gran Fuerte area was surveyed with three different resolutions of data and the reliability was compared. Figure 4 shows area 1 with data gathered in the 2006 survey with single pinging and half the resolution of the 2014 basic survey, area 2 is the area covered by at standard $100 \%$ coverage with a $3 \times 3 \mathrm{~m}$ backscatter and $15 \times$ 15 bathymetry coverage and area 3 was covered by two passes producing a merged smoothed and averaged backscatter data set covering twice this area (at 200\%).

As with all backscatter data, even of the highest resolution, the base data showed, in addition to geological influence high backscatter, high values that occur due to the angle of incidence of the beam with the seabed; this so called grazing angle of the beam has a profound effect on the backscatter values and, although all the processing software used attempt to compensate to some extent for this variation, none eliminate it. The most obvious example of this phenomenon is the "nadir line" which reflected the track of the vessel over a flat seabed. If the seabed is not flat, the nadir spreads out and often intensifies reflections off any slope that faces towards the vessel as it passes and, by contrast, any slope angled away from the vessels track will have a reduced backscatter 


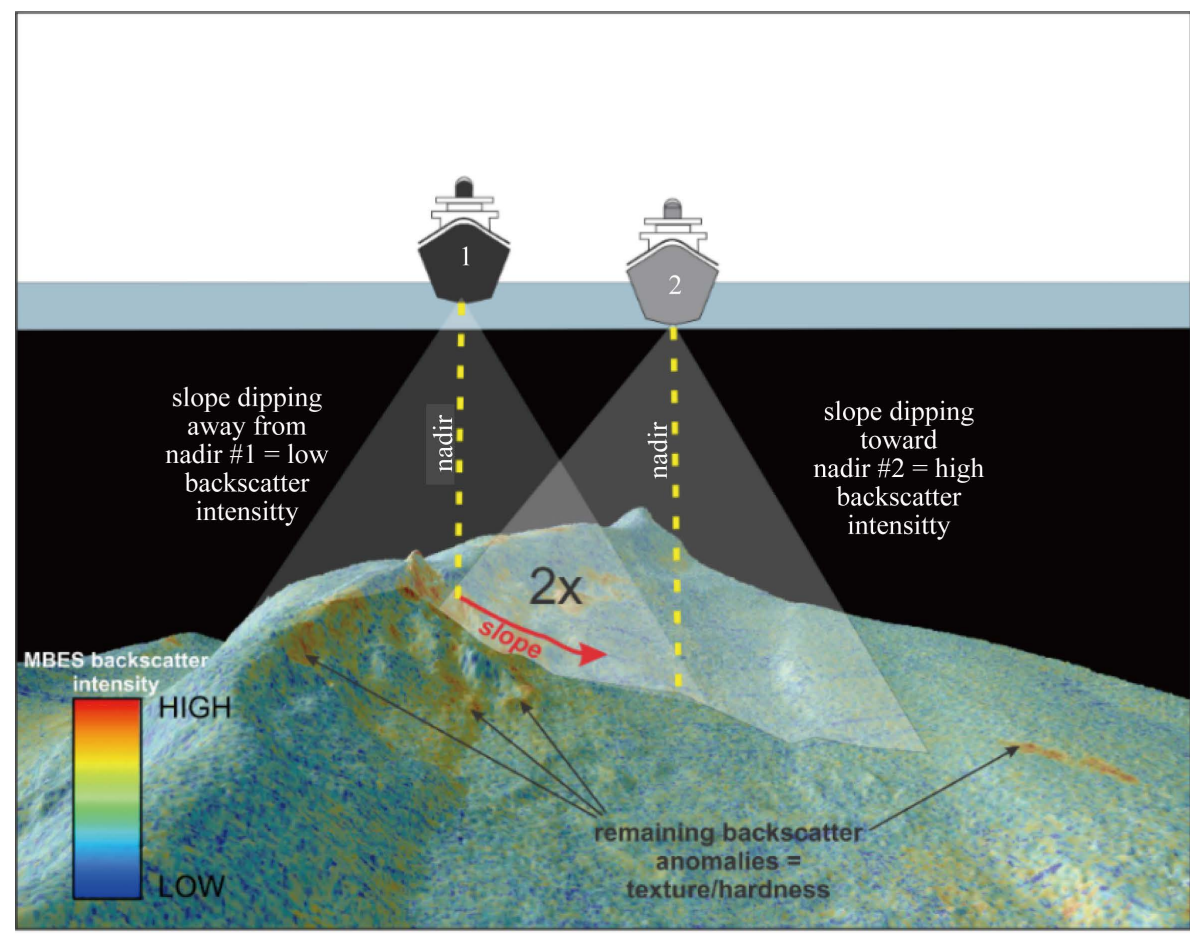

Figure courtesy of Kelley Brumley Fugro.

Figure 2. Method used to obtain $200 \%$ coverage. Each area of the seabed is acoustically examined twice from two opposite directions and angles. The backscatter data is then merged to eliminate the grazing angle and positional effects on the backscatter map.
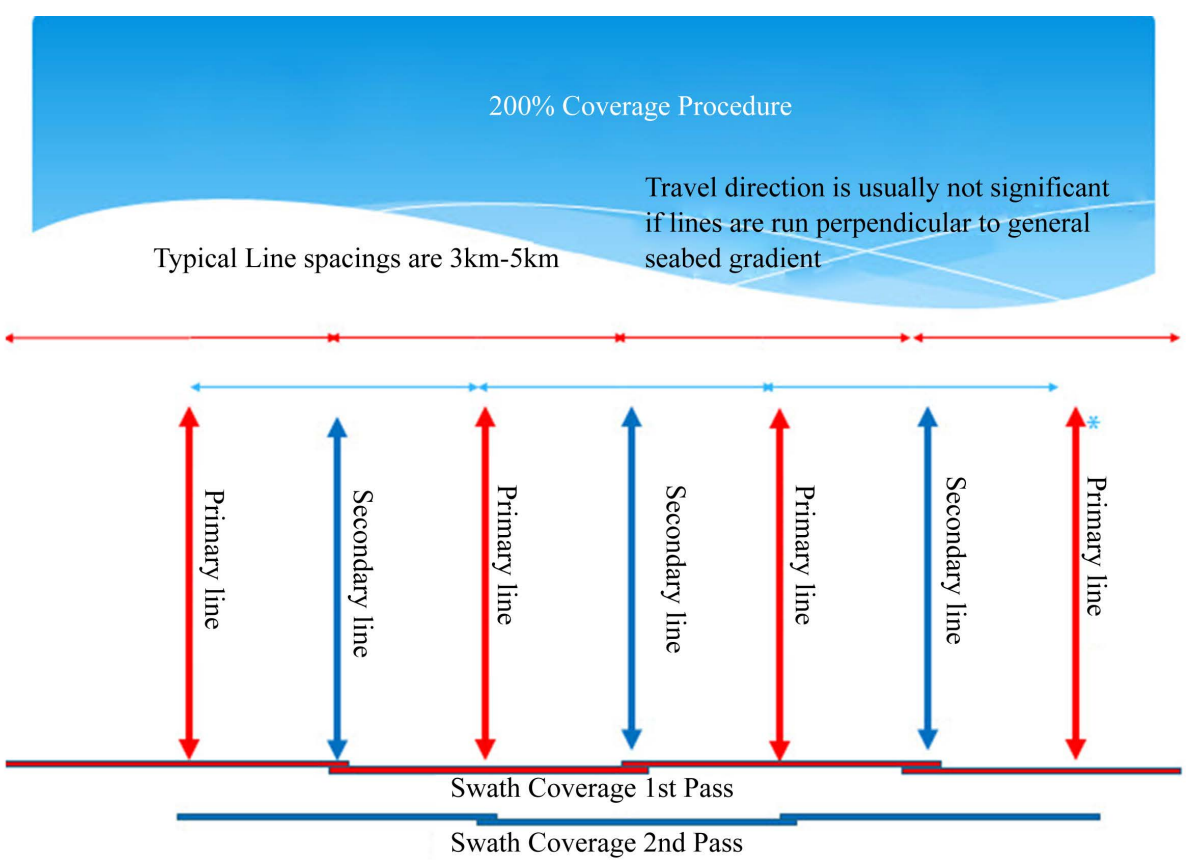

Figure 3. Procedure to cover the same area twice at different grazing angles with the survey vessel.

signature. Results with a $200 \%$ coverage showed that these artefacts can be nullified with each area of the seabed receiving acoustic pulses from two opposite directions as shown in Figure 2. Double coverage process of first pass, second pass and the final merged data are shown in Figures 5(a)-(c). 


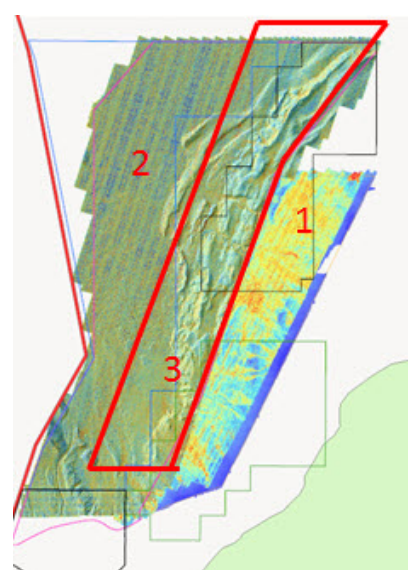

Figure 4. The Gran Fuerte survey area and different levels of coverage. Area $1=2006$ survey covering $2800 \mathrm{~km}^{2}$, Area $2=2014$ survey with $100 \%$ backscatter data coverage, area $7300 \mathrm{~km}^{2}$; Area $3=2014$ survey with $200 \%$ backscatter data coverage, area $4100 \mathrm{~km}^{2}$.

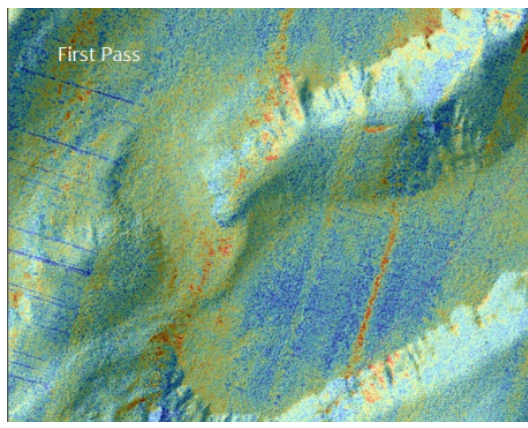

(a)

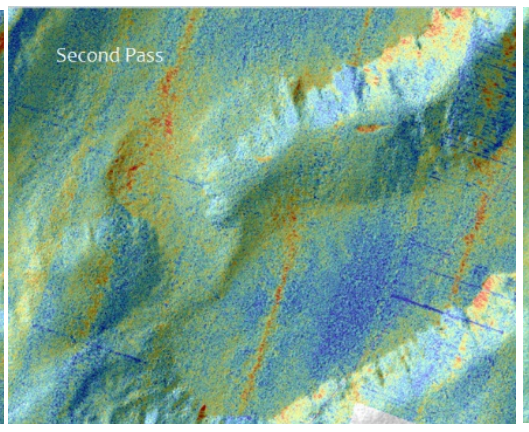

(b)

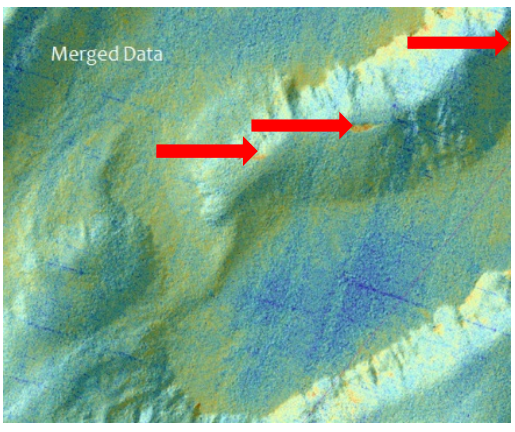

(c)

Figure 5. (a) First pass (100\% coverage) showing 2 Nadir lines and high backscatter values on slopes; (b) Second pass showing 3 Nadir lines and high backscatter values at different locations on slopes; (c) Merged data (200\% coverage) showing the area clear of artefacts with the high backscatter remaining clearly identifying cold seeps (red arrows).

Results showed how most backscatter artefacts seen in first pass (Figure 5(a)), and second pass (Figure 5(b)) are lost and all are significantly reduced when the data are merged (Figure 5(c)). The "clean" data (Figure 5(c)) is far simpler to interpret the remaining high backscatter anomalies, where three locations (red arrows, Figure 5(c)) identify the possible cold seeps and the structured benthic communities associated. In this example, the remaining geological causes of high backscatter shown here in an intermediate yellow color occur mainly at the base of slopes where sediments have washed down and are deposited as small outwash fans (Figure 5(c)).

Area 3 (Figure 4) of Gran Fuerte (35\% of the whole area) surveyed at 200\% coverage showed a better and more complete geological map of the seabed, with cold seeps readily identified and delimited due to the presence of authigenic carbonates and structured benthic communities creating high backscatter anomalies. Confirmation of the accuracy of the previous assessment comes from the recovered piston cores containing seep fauna remains (chemosynthetic communities; Figure 6) and/or hydrocarbon—charged sediments in the locations predicted.

Of 177 seep locations identified unrelated to clear expulsion features and based on backscatter evidence alone, 59 were cored and 55 cores were successful in identifying and confirming the presence of a cold seep (93\% accuracy) associated with benthic communities. One core missed the targeted seep and time did not allow a more accurate re-drop but water column gas plume had already confirmed the seep's existence. In the area of 200\% coverage, all of the 55 seeps identified and cored were confirmed at 100\% accuracy, and found to be precisely assessed. Another 32 expulsion features (apart from the 177 identified by backscatter alone, for a total of 209 seep locations) were identified and 20 of them were cored and proven to be hydrocarbon related features; other 


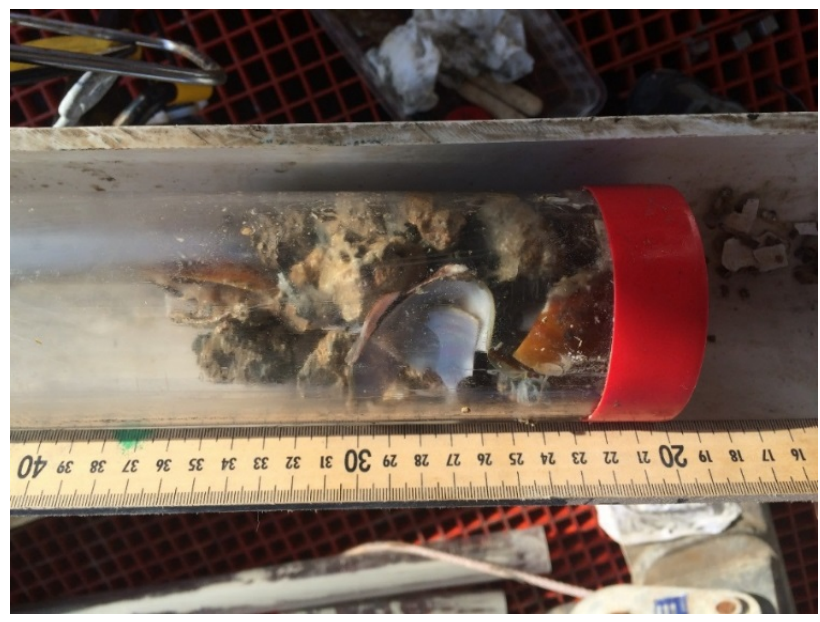

Figure 6. Evidence of chemosynthetic communities recovered in some of the cores. This was one of the rare occasions when live organisms were recovered. Most samples directly on seeps recovered carbonate rubble and bleached shells debris.

two cores were dropped on features that were not clearly understood in order to investigate those locations; one appears to be a sand expulsion feature and another mound was confirmed to be a large draped block in a debris field. The rate of success was $91 \%$ for identified expulsion features based on bathymetric evidence. Lastly, 43 locations revealed gas plumes in the water column. All of these locations were identified from the multibeam data as already mapped seep locations.

Seep size and limits were accurately established. Figure 7(a) and Figure 7(b) shows two cases in Gran Fuerte, where the drop locations of the cores included two that were only between 6 and $9 \mathrm{~m}$ away from the edge of the chemosynthetic community and these drops resulted in soft clay cores with no evidence of chemosynthetic community and hydrocarbon levels at or barely above background levels. Thus confirming how sharply defined such chemosynthetic communities are and how precisely they are associated with the presence of the hydrocarbons.

The 200\% coverage allowed the classification of the quality, expressed as density, of the chemosynthetic communities associated with the seeps. The most obvious feature, apart from size, is the backscatter values and consistency of those values within the seep area. This variability allowed a categorization of "seep quality" to be established. Consistently high backscatter values over the seep area appear to correspond to high density of chemosynthetic communities, suggesting live and presumably active communities. Such occurrences were designated as "Dense Seeps"; of all seeps identified, 112 were recognized as dense seeps.

Other seeps have far less consistency about the high backscatter signal and are patchy. They are still very likely to be seeps with high backscatter again related to chemosynthetic activity, but they may be partly covered with recent sediment and may possibly be no longer active or only partly active. These seeps are categorized as "Low Density Seeps" and 62 of all locations fall into this category. A final category includes a number of locations that may be caused by other geologic processes that increase backscatter values and may be wrongly included as seeps in the survey or may be mainly covered with recent sediment and represent extinct seep communities. The acoustic signals can penetrate into the sediment and in theory relict seeps should still be detectable; these locations have been designated as "Traces" and 35 of all locations fall into this category. Figure 8 shows an example of seep quality variation. This classification allows all potential likely seep locations to be included and is considered a valuable safeguard in ensuring the environmental assessment is complete.

Extensive drift camera surveys were carried out in strategic areas of the Gran Fuerte area, covering previously identified seeps; these camera surveys confirmed the presence of chemosynthetic communities in the locations previously predicted and also confirmed the seep quality categories established as being valid, as shown in Figures 9(a)-(c).

No elevated sea-mounts and no ridges or evidence of hard substrate were found in the two main areas of study (Figure 1); all the ridges and elevated areas that did exist were the result of fold belt geological processes and 


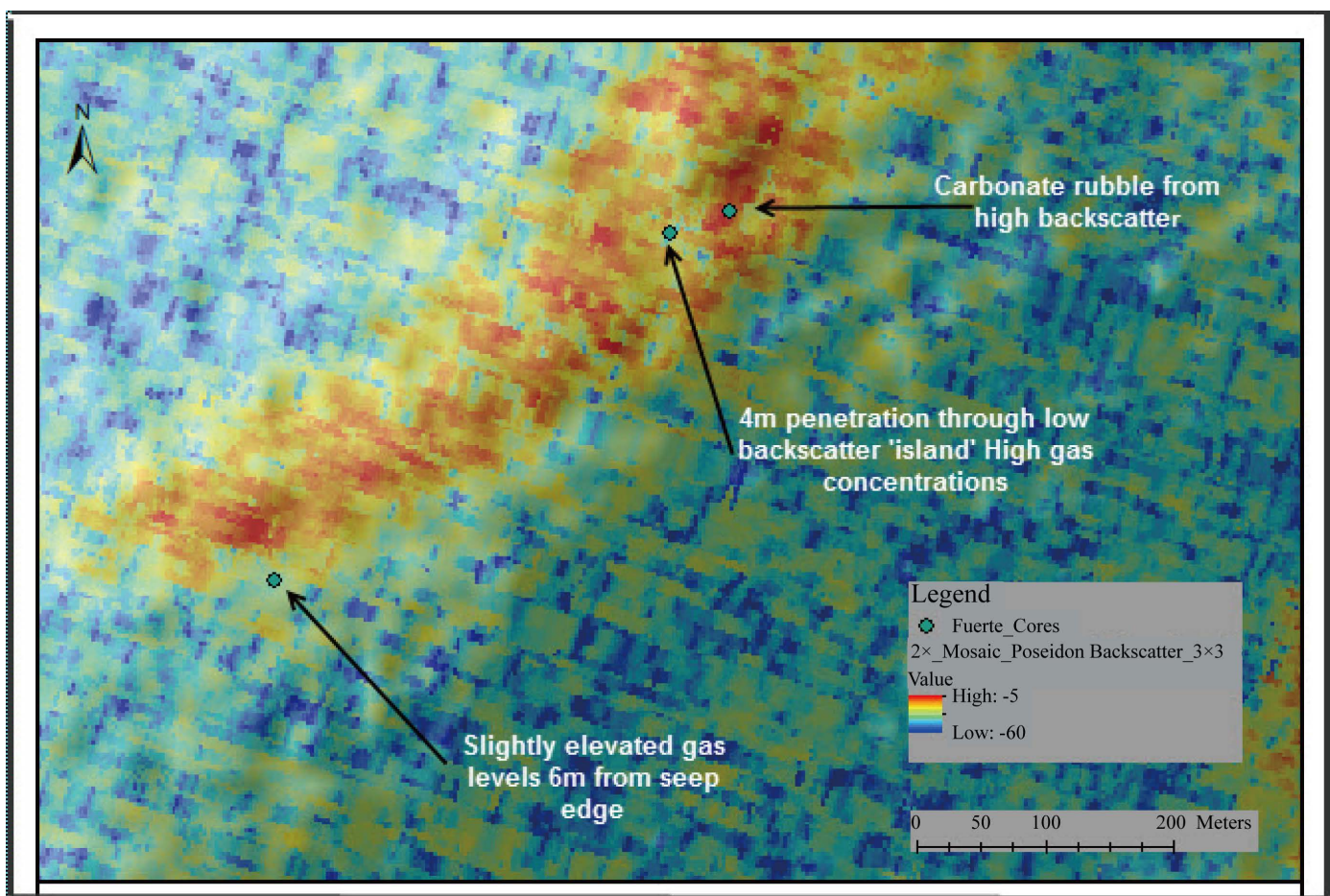

(a)

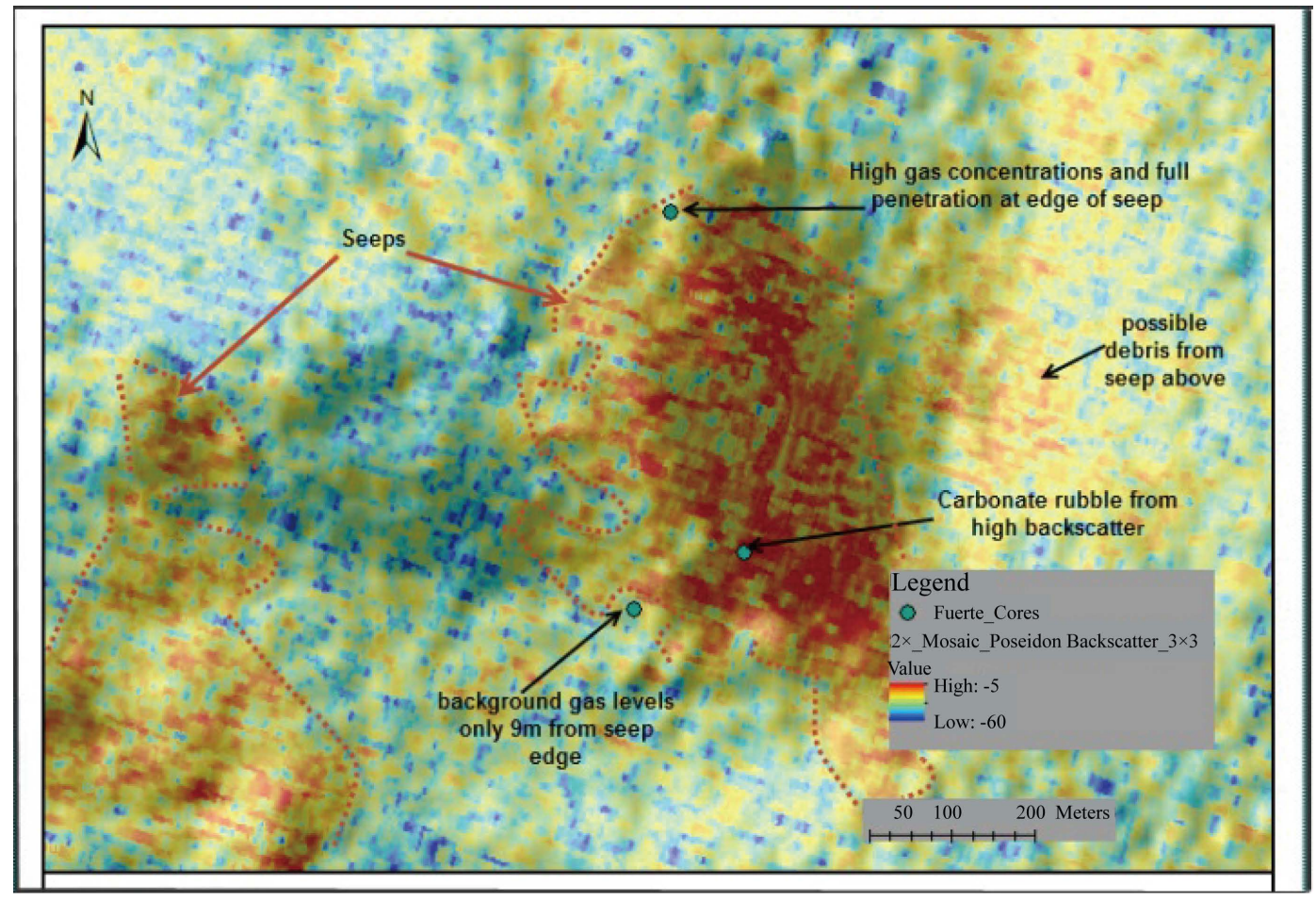

(b)

Figure 7. (a) Seep 32 with three cores, one with minimal recovery of carbonate rubble dropped in the high backscatter area, another dropped in a small gap in the high backscatter, within the seep, with high hydrocarbon content and the last one, just 6 m outside the seep boundary with hydrocarbons levels barely above background; (b) Seep 206 is an expulsion feature making a low mound partly covered with high backscatter, one core was positive for seep fauna on the high backscatter whereas the second core just $9 \mathrm{~m}$ from the sharp edge to the high backscatter had no significant hydrocarbon content and no seep fauna recovered. A third core just in from the edge by probably $<5 \mathrm{~m}$ had full recovery and elevated gas levels. 


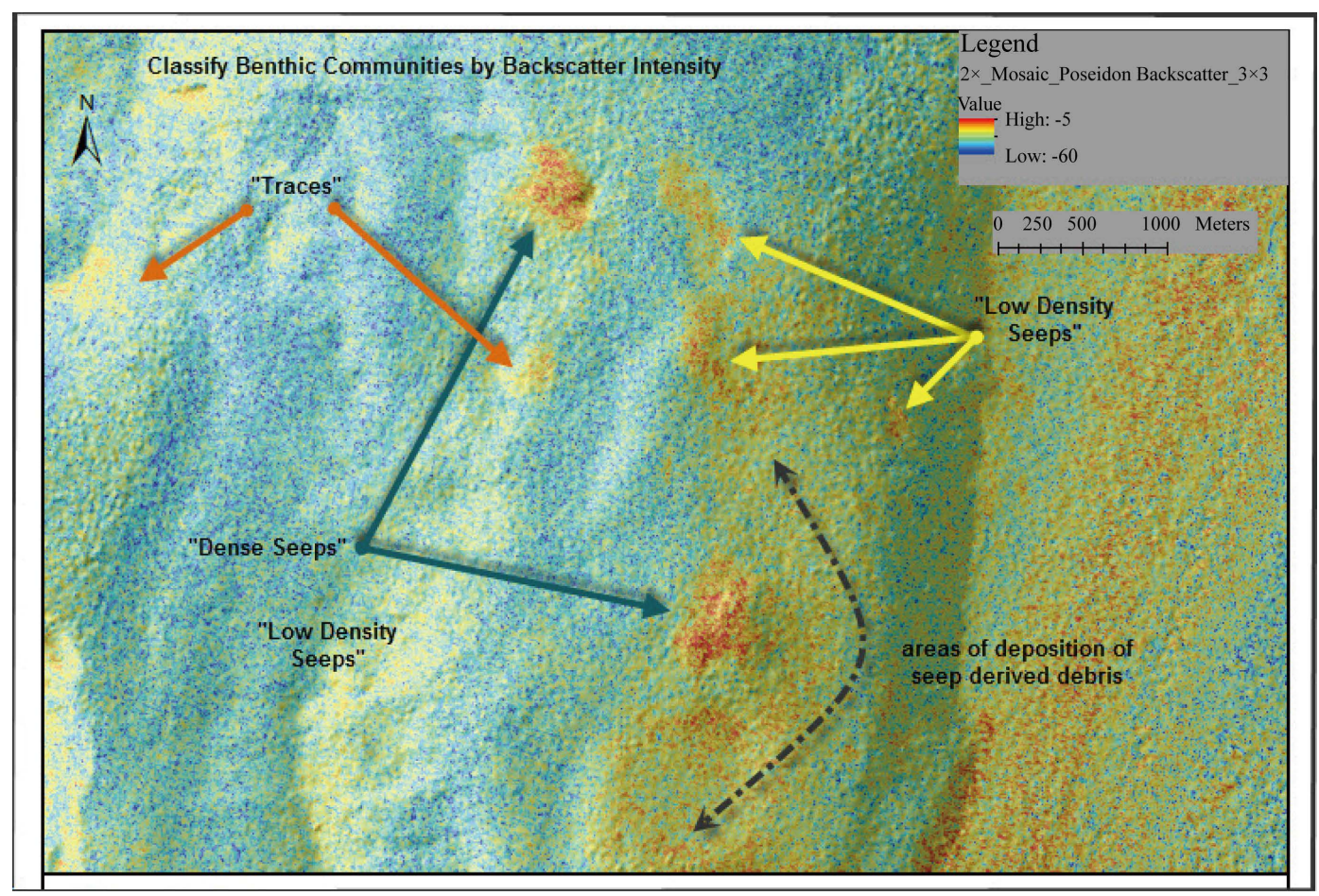

Figure 8. Blue arrows indicate two "Dense Seeps" with uniform high backscatter values. Yellow arrows indicate "Low Density Seeps" with some high but generally lower backscatter values. Brown arrows indicate "Traces" with no high backscatter but with a discrete appearance. In addition there is a spread of moderate backscatter downslope from some of the seeps; these areas are interpreted as debris fans downslope from the existing benthic communities.

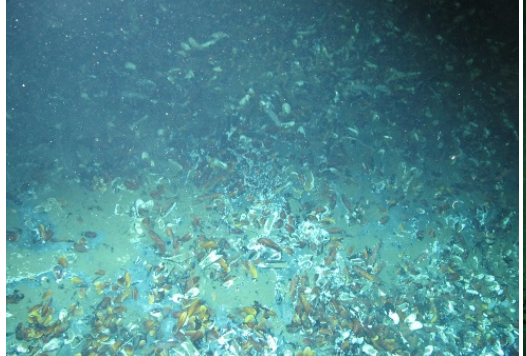

(a)

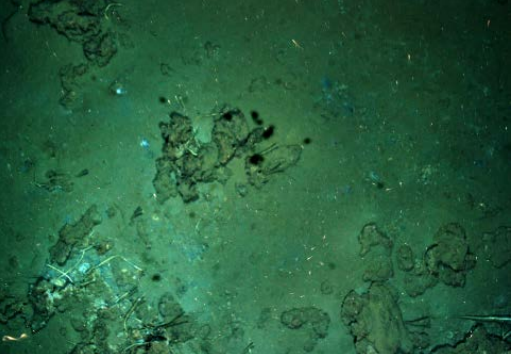

(b)

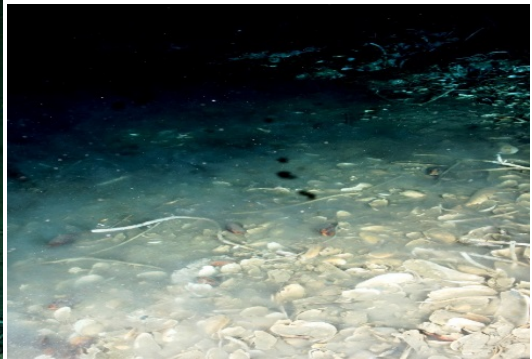

(c)

Figure 9. Different images of chemosynthetic communities in the Gran Fuerte area. (a) Dense seep includes preliminary identified as live Bathymodiolus spp. and Calyptogyna spp. shells ( brown); (b) Low density seep, with bacterial mats, small areas of authigenic carbonate and tube worms remains; (c) Traces-macro fauna debris downslope from other active sites, (Anadarko 2014, 2015 Drift Camera Surveys, with TDI, SERPORT and CSA).

did not expose any competent strata at the seabed. However, to the east of the Gran Fuerte area, two ridges with exposed "rock" at 400 - $800 \mathrm{~m}$ depth were found in the 2006 survey (Figure 10). Although it is not yet confirmed for this site, these locations may have a high probability of having deep-water corals, such as stony corals like Madracis myriaster already found in the southern Colombian Caribbean [6]; these corals usually require exposed hard substrate for attachment [7].

\section{Discussion}

\subsection{Multibeam Data and Backscatter Interpretation}

Seeps were identified using the multibeam data and then targeted for coring to obtain geochemical samples. This 


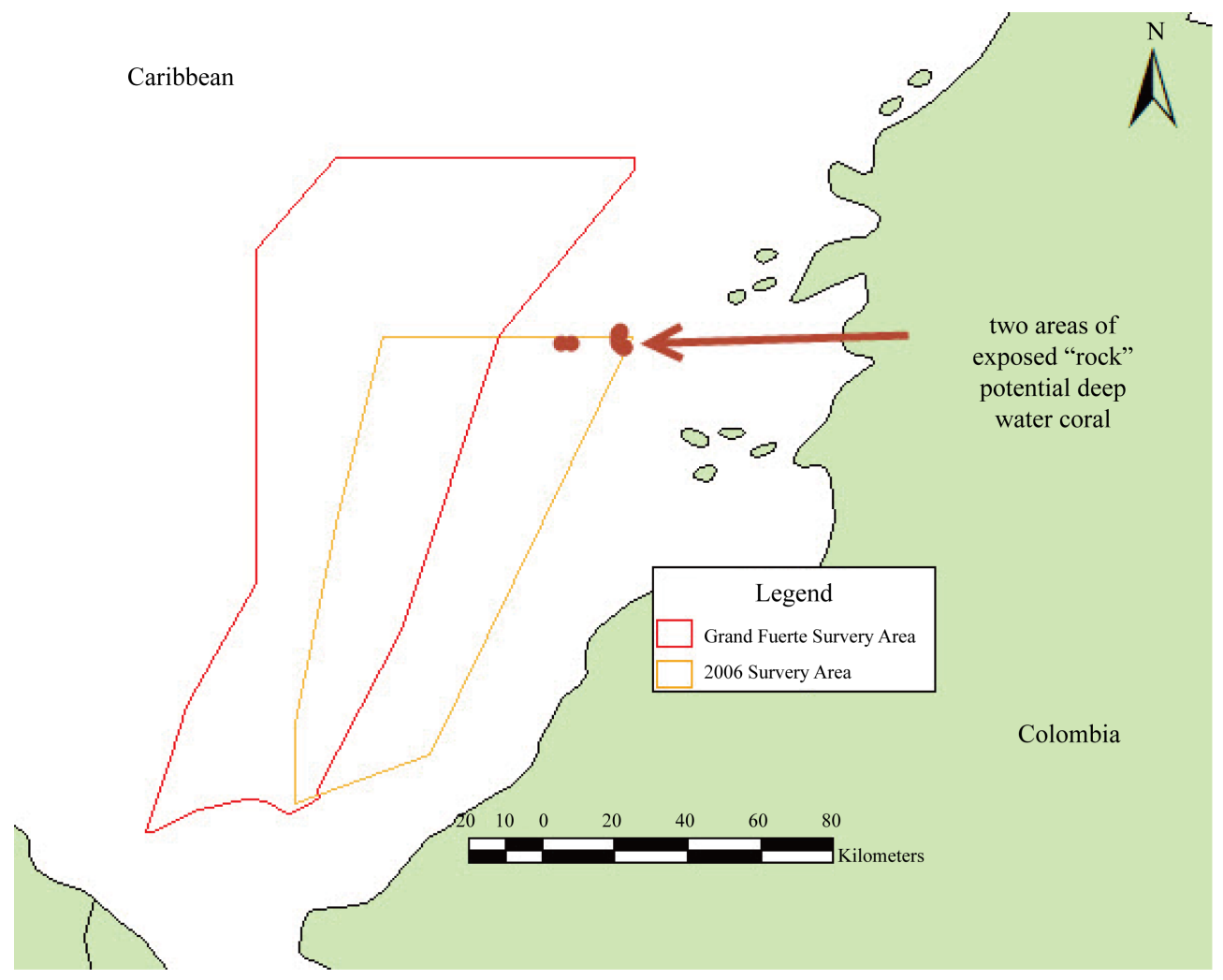

Figure 10. Two potential locations for deep-water corals.

kind of survey has now been performed for many years following the development of high quality bathymetric and backscatter data available for deep sea surveys. The technique is now an accepted exploration tool for identifying deepsea areas with potential for development of hydrocarbon resources by locating and geochemically sampling those cold seeps [8] [9]. The new integrated and improved method presented here allowed far higher reliability to be attached to the interpretation of the data and added the potential for discriminating the quality of various seeps using the backscatter mapped characteristics of each seep. The information is also used to form the basis for any surface geo-hazard assessment and planning to ensure the safety of any seabed infrastructure, as well as to identify areas of environmental or archeological interest.

The high resolution backscatter values reflect the hardness of the seabed interface and the very shallow strata close to the seabed; high backscatter values can be obtained from sandy or gravelly seabed sediment, such as thin interleaved layers of silt/sand and clay, that in deep-water typify mass transport or mass wasting deposits such as turbidites, debrites, outwash fans, slumps, etc. High backscatter values are also found in consolidated (strong) sediments, volcanic substrate exposed at the seabed or very close to the seabed, and irregular small scale roughness of the seabed. The hardness of the authigenic carbonate and the roughness of the macro fauna covered surface make structured benthic communities have high backscatter values as a valuable property from the environmental perspective.

\subsection{Cold Seep Identification}

The innovation of the method described here consists of the exclusion of the geometric artefacts associated with multibeam backscatter by the ensonification of the seabed from two opposing angles, leaving nullified these artifacts and leaving only the geological reasons for variation in backscatter values. This procedure allows a far more accurate interpretation of the geological processes causing high backscatter values, including any high backscatter anomalies that can be the result of structured benthic communities associated with cold seeps. Another significant advantage of merging a second data set of the same area at different angle is that random backscatter noise and weather effects are also diminished; this is most significant when looking in detail at locations to define the edges, extent and probable density of structured benthic communities representing the che- 
mosynthetic communities of the Gran Fuerte area.

Anaerobic oxidation of methane results in the formation of authigenic carbonates which forms hard-grounds on the seafloor (e.g. [10]), which are associated with chemosynthetic communities exploiting the presence of reduced, chemical rich fluids on the seafloor (e.g. [11]). The increased hardness and roughness of the seafloor that results from both authigenic carbonates and chemosynthetic communities are identifiable in MBES data as high intensity backscatter patterns; these communities may not be associated with any clearly recognizable bathymetric feature although some large and active seeps may develop shallow irregular and uneven mounds that can be seen at a very detailed scale, often referred to as bioherms. The majority of the structured benthic communities associated with cold seeps on Gran Fuerte have been identified and delimited by a clear backscatter signature. Faulted Fold Belts like the Sinú Fold Belt are likely to have a majority of the seeps that are present identified by backscatter only.

Other data can be used to identify potential cold seeps as their location can be related to sub-surface features in seismic and sub-bottom profiler data, typically gas chimneys and amplitude anomalies. The resolution of such data however, is rarely sufficient to allow definitive sampling. An example of this lack of accuracy can be taken from Gran Fuerte geochemical exploration data where 37 cores were reserved for locations without apparent MBES defined backscatter or bathymetric cold seep signatures but appeared as likely seep locations based on seismic data alone. None of these cores dropped on features identified by seismic data alone revealed any clear geochemical signatures associate with cold seeps.

Bathymetric features can also indicate the likely presence of shallow gas. These features are termed expulsion features and their relationship with structured benthic communities is not as straightforward as those seeps identified by backscatter alone. The expulsion features are the result of gas charged mud diapirs rising through the sediment column forming mounds, domes and mud volcanoes. They are in general larger in area than the backscatter defined features and are defined by their vertical expression which is far greater than the backscatter identified cold seeps. They are often 100's of hectares in extent reaching 10's to 100's of meters above the surrounding seabed. Although these expulsion features are less common on the Gran Fuerte area than backscatter defined cold seeps, this reflects the geological structure. In areas, particularly basins with relatively undisturbed strata, the trapped gas may not have any structurally controlled seepage paths to the surface as they have for instance in the folded and faulted Sinú Fold Belt of much of Gran Fuerte. The gas, thus trapped by the geology, travels up with the gravity driven movements of the mud diapirs to reach the shallow sub-surface [12].

\subsection{Cold Seep Identification, Improvements Using 200\% Coverage}

From coring these features both in Colombia and across the world plus relatively recent academic investigations [4] [13], it appears unusual for all the surface of an expulsion feature to be associated with chemosynthetic communities. Partly because of the slope effect that is present on standard $100 \%$ coverage, identifying where on these features structural benthic communities do exist has always been difficult. Backscatter data is still the most reliable data to identify the parts of these features where shallow gas can be accessed by the chemosynthetic communities that form these structured benthic communities. The $200 \%$ coverage significantly improved the recovery rate of successful geochemical cores from expulsion features on Gran Fuerte as the slope artefact on cones, mounds and mud volcanoes, previously masked the true areas of high backscatter that could be due to chemosynthetic communities.

A group of expulsion features not represented well on Gran Fuerte but commonly encountered in other surveys are collapse features associated with liquid or gas expulsions from the seabed, known commonly as pockmarks; such features are more rarely associated with chemosynthetic communities, and this is probably because the episodic nature of such expulsions, that can cause collapse of the seabed forming the pockmarks. They cannot sustain and allow a long-lived chemosynthetic community to develop and the formation of many pockmarks is totally unrelated to hydrocarbon expulsion [14]. Identifying chemosynthetic communities in a pockmark with continued hydrocarbon flux is present has proven very difficult with traditional survey methods; the dish like form of a pockmark concentrates the backscatter acoustic energy giving falsely elevated backscatter values. Double coverage has great potential in identifying pockmarks having hydrocarbon flux after formation, but in the areas surveyed in Colombia (Gran Fuerte area) there were no pockmarks present.

\subsection{Seep Sampling-Improvements with $200 \%$ Coverage}

Seeps occur in geologically driven "hotspots” and to support associated chemosynthetic communities they re- 
quire both the oxygen in sulfate ions and the hydrocarbons; thus the sulphate-methane transition zones need to be very close to the seabed. It has been estimated that this transition zone must be within $1 \mathrm{~m}$ of the seabed to allow the methane and oxygen from the sulphate ions from seawater to both be available [3]. The balance can be disturbed if the flux decreases or becomes unreliable and the sulphate-methane transition deepens or the flux increases and the sulphate ions cannot penetrate the seabed. So, the location of high hydrocarbon flux at the seabed is controlled by geological structures and properties of the near surface sediments; in the Colombian surveyed areas, folds, faults and outcrops of permeable strata appear to control much of the distribution of the seeps identified.

Identification of seeps from MBES data began when backscatter data was first collected and processed to provide reliable indicators of seabed properties [8]. After many years of academic research, an estimated 75 commercial surveys of this kind had been performed by 2013 (AOA Geophysics Commercial data) and the lead author has taken an active part in 23 of these surveys from 2007 to 2015. The ground validation of the interpretations with piston coring has allowed constant updating of the interpretative techniques and provides the best indication of the accuracy of the interpretation. In addition, seabed drift camera surveys have been carried out and for the present survey provide confirmation of the MBES data interpretations of cold seeps with the chemosynthetic communities associated, giving a good quality assessment of the methodology for the Gran Fuerte data gathered. Cores and drift camera surveys confirmed that the principles applied in the MBES data interpretation were correct and the interpreted data was of the highest quality and reliability, and thus can be applied with confidence to identify seeps and structured benthic communities associated.

Recovering cores with good penetration on these structured benthic communities to provide both geochemical and environmental data is difficult because a piston core is designed to take samples from soft ground and not the hard ground of these communities. The target for a successful core drop is thus the edge of a seep and the edge of the seep community and not on the seep itself. Before this $200 \%$ coverage technique was developed the identification of the edges of these seeps was not reliable enough to allow anything other than an element of good luck to achieve a good recovery. With the surveys carried out in 2014/2015 on Gran Fuerte, and on other surveys carried since Gran Fuerte, which have include 200\% coverage, a far more reasoned approach can be made to core positioning. The percentage of cores with good penetration increased from $40 \%$ to $70 \%$ as the edge of seeps was targeted from the areas with $100 \%$ coverage to those with $200 \%$ coverage. The remaining $30 \%$ missed were those drops that either still dropped in the high backscatter defined seep or drifted too far from the seep edge; the accuracy limitations of the ultra-short baseline GPS positioning system itself which at best is around $0.25 \%$ of the water depth, and the physical difficulty of holding a core directly from a mobile platform (vessel), makes that dropping it in the exact desired position accounts for that remaining 30\% inaccuracy. This improvement in accuracy and the deliberate targeting of the edges of seeps also reduces the likelihood of damaging live communities with the cores even though this likelihood is already very small.

\subsection{Cold Seep Activity Indications from Backscatter}

Notwithstanding these inherent inaccuracies of positioning it was evident from the survey results that the edge of these seeps are well defined and drops more than $10 \mathrm{~m}$ away from the seep edge produced neither macro fauna or seep geochemistry. The shapes of these communities in the Gran Fuerte area are often complex and very irregular and the area covered by each seep identified was equally variable. The $200 \%$ coverage methodology allowed the identification of even small patches, the smallest found in this area being only 0.16 hectares in size. Backscatter data consistency also allowed the categorization of the different levels of significance for the chemosynthetic communities found and the variability can be seen in the examples in Figure 8 .

Most recoveries on dense seeps were bleached shell debris and carbonate rubble, but a few samples (7\%), such in Figure 8(a), showed a mass of live macrofauna. Therefore it is considered that seeps having high backscatter values over the majority of the seep area, which are categorized as dense seeps, may be of strategic ecological significance. "Low Density Seeps" have no bathymetrically recognizable carbonate mounds (bioherms) and drift camera evidence suggests that compared to the dense seeps, the live fauna is more sparse and intermittent, typically consisting of bacterial mats and occasional tubeworms. Chemosynthetic communities categorized as "Traces" can be debris from nearby active seeps as seen in Figure 8(c) or possibly in-situ but extinct communities covered with sediment that backscatter data can still detect.

Sedimentation rates appear high in some parts of the Gran Fuerte area with the Atrato, Sinú, San Jorge and/or 
Magdalena rivers, as the main sediment contributors. Seeps were less common in the eroded canyons and sediment channels than on the elevated ridges of the Sinú Fold Belt; however the subsurface structural influences of faults, folds and outcrops appear more significant than the sedimentation regimes in determining whether structured benthic communities exist associated with cold seeps.

Structured benthic communities associated with cold seeps and those formed by deep-water corals not tied to cold seeps should both be identifiable using this techniques, all areas identified on Gran Fuerte area were associated with cold seeps; the water depths in this area (700 $\mathrm{m}$ in the south to over $2500 \mathrm{~m}$ in the north) were presumably too deep to expect deep-water corals, and in fact no deep-water corals were found here. There are three sites with deep-water corals between $70 \mathrm{~m}$ and $150 \mathrm{~m}$ depth identified in the Colombian Caribbean [6]; other corals were found corals in the same area at between $120 \mathrm{~m}$ and $180 \mathrm{~m}$ depth [15]. Deeper surveys have also been carried out, analyzing 210 stations in 8 sectors of the Colombian Caribbean between $10 \mathrm{~m}$ and $510 \mathrm{~m}$ deep, finding a diversity of deep-water corals [16], and deep-water corals were also studied in the Greater Caribbean area with more than 204 stations and a depth range between 60 and $5400 \mathrm{~m}$ depth [17]; their stations with deep water corals in the south Caribbean, most representative species were present no deeper than $480 \mathrm{~m}$. The baseline studies performed on Gran Fuerte as a requirement for the environmental licenses showed no presence of deep-water corals in any of the box corer samples in the Gran Fuerte area as well [18]. However, the analysis of the 2006 survey did show two shallow $(400-800 \mathrm{~m}$ ) ridges of hard substrate that is relatively near to a priority conservation site where deep-water corals were already reported (Figure 9). These ridges are outside any current exploration oil \& gas contract areas and might be inside the recently created Deep-Water Coral National Natural Park. A recent survey with a ROV by the Marine and Coastal Research Institute (INVEMAR), National Natural Parks and ANH has confirmed stony deep-water corals such as Madracis myriaster in both channel and plain grounds up to $230 \mathrm{~m}$ depth in this national natural park (Henao, A., National Natural Parks; Pers.Com.).

\subsection{Areas of Significance for Biodiversity-Landscape Models Compared to Observed Occurrence}

The ASBs in Colombian Caribbean [5] were assigned based on the identification of 32 conservation landscape objectives at different biological organization levels and geographical scales, associated to a high richness and biodiversity, according to the conceptual frame [19] for eco-regional planning for conservation. Their methodology used a "coarse filter" based on the seabed morphology (e.g. plains, hills, ridges, escarpments, canyons, channels, etc.) ranking places by three main attributes, depth, substrate hardness and roughness. They also established a "fine filter" consisting of vulnerable species (e.g. deep-water corals, species of reduced environments) if identified. The method described and validated in this paper uses a far higher resolution for MBES than that one used in the ASB identification [5]. The present method identifies more accurately the seabed morphology than the one used by [5] covering areas both in and outside of the ASBs, in the Gran Fuerte area. Results showed that $99 \%$ of the surveyed area has a soft substrate and that "coarse filter" marine landscapes are not necessarily related with a higher probability of finding "fine filter" objectives of conservation in the ASBs. The chemosynthetic communities were confirmed in Gran Fuerte in depths from 1000 to $2500 \mathrm{~m}$ depth for the first time in the Colombian Caribbean, both in and outside ASBs. ASB 9 and the greater part of ASB 1 that were surveyed with this method showed no chemosynthetic communities or any other structured benthic communities; chemosynthetic communities are the only structured benthic communities found both inside and outside ASB 6 and ASB 8 in the Gran Fuerte area.

On the other hand, results showed how chemosynthetic communities are tied exclusively to cold seep locations and how cold seep locations and associated gas plumes were not dependent on large scale seabed morphology or large scale irregularity (roughness) of the seabed, which were the main coarse filter features used by [5]. Instead they occurred in areas of soft sediment where they could be detected readily by the hardness and roughness of each cold seep and associated chemosynthetic community. The location of the seeps is controlled by the geological structures present that allow the passage of hydrocarbons to the seabed. For example, ASB 6 is a typical area of the Sinú fold belt and cold seeps here follow faults often cross-cutting the large scale geomorphologic structures that dictated the boundaries; Figure 11 shows seeps found in a part of ASB 6, occurring on both plains and ridges following faults and other deeper seated geologic structures not controlled or influenced by the large scale geomorphology, therefore not correlated with ASB boundaries (based on coarse filter marine landscapes). 


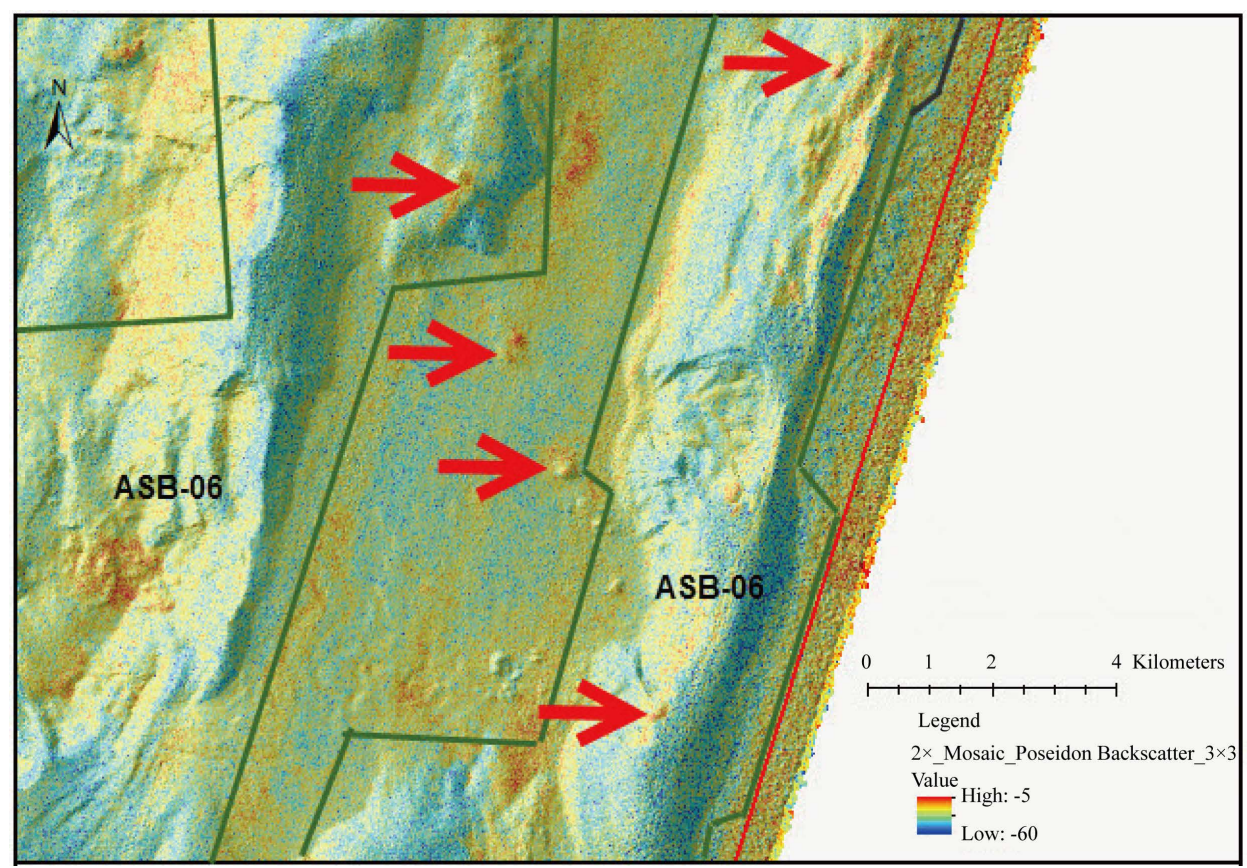

Figure 11. Confirmed chemosynthetic benthic communities (red arrows) found in both plains and hills, and inside or outside an ASB. "Plains" are not considered in the ASB, while "hills" are in the ASB. Four of these seeps follow a fault line across these geomorphological features.

Focusing just on currently designated ASB areas in an effort to find structured benthic communities could leave an important number of cold seeps (and chemosynthetic communities associated) unidentified. Instead, the use of this new methodology based on $200 \%$ coverage backscatter and high resolution bathymetry data presented in this survey, can be relied upon to identify all significant, sizeable and active chemosynthetic communities that would have an environmental significance.

\section{Conclusion}

This survey allowed implementation of an innovative method to find cold seeps and structured benthic communities associated with them, using MBES backscatter data with double coverage of the same area. The high resolution backscatter data interpretation, the gas plume identifications, the core samples and drift camera evidence, which are all correlated, allow a very high level of confidence to be attached to the identification of structured benthic communities associated with cold seeps. The method allows the seep map produced to be used as a precise geo-hazard map to ensure the oil \& gas industry can avoid these areas of shallow gas for further developments; and at the same time, it provides important new knowledge on the deep sea biodiversity for the Colombian Caribbean, reporting for the first time the presence of chemosynthetic communities over $1000 \mathrm{~m}$ depth, which are not necessarily related to the ASBs previously identified.

\section{Acknowledgements}

Authors want to thank to all the people involved in Anadarko headquarter in Houston, Anadarko office in Colombia, Ecopetrol, the companies involved in field work such as TDI, SERPORT and CSA, captains and crew of the vessels used, and people at shore base who were committed in the logistics for all the research campaigns. Special thanks go to Kelley Brumley for Figure 2 and appreciation to Jim Gharib at Fugro Geoconsulting Inc. and Dan Orange and Oro Negro Exploration for the debate, ideas and discussions before and during the data acquisition.

\section{References}

[1] Fisher, Ch., Roberts, H., Cordes, E. and Bernard, B. (2007) Cold Seeps and Associated Communities of the Gulf of 
Mexico. Oceanography, 20, 69-79. http://dx.doi.org/10.5670/oceanog.2007.12

[2] Kennicut, M.C., Brooks, J.M., Bidigare, R.R., Fay, R.R., Wade, T.I. and McDonald, T.J. (1985) Vent Type Taxa in a Hydrocarbon Seep Region on the Louisiana Slope. Nature, 317, 351-353. http://dx.doi.org/10.1038/317351a0

[3] Foucher, J.P., Graham, K., Westbrook, A.B., Ceramicola, S., Dupré, S., Mascle, J., Mienert, J., Pfannkuche, O., Pierre, C. and Praeg, D. (2009) Structure and Drivers of Cold Seep Ecosystems. Oceanography, 22, 93-109. http://dx.doi.org/10.5670/oceanog.2009.11

[4] Levin, LA. (2005) Ecology of Cold Seep Sediments: Interactions of Fauna with Flow, Chemistry and Microbes. In: Gibson, R.N., Atkinson, R.J.A., Gordon, J.D.M., Eds., Oceanography and Marine Biology: An Annual Review, Vol. 43, CRC Press-Taylor \& Francis Group, Boca Raton, 1-46. http://dx.doi.org/10.1201/9781420037449.ch1

[5] Alonso, D., Segura-Quintero, C., Torres, C., Rozo-Garzon, D., Espriella, J.M., Bolaños, J. and Lopez, A.C. (2010) 12. Areas Significativas para la Biodiversidad. Ed., INVEMAR. Biodiversidad del Margen Continental Colombiano. Serie de PublicacionesEspeciales, Invemar, 393-423.

[6] Reyes, J., Santodomingo, N., Gracia, A., Borrero-Perez, G., Navas, G., Mejia Ladino, L.M., Bermudez, A. and Benavides, M. (2005) Southern Caribbean Azooxanthellate Coral Communities off Colombia. In: Freidwald, A. and Roberts, J.M., Eds., Cold Water Corals and Ecosystems, Erlangen Earth Conference Series, 309-330. http://dx.doi.org/10.1007/3-540-27673-4_15

[7] Morgan, L.E. (2005) What Are Deep-Sea Corals? Current. The Journal of Marine Education, 21, 2-4.

[8] Orange, D.L., Yuna, Y., Maher, N., Barry, J. and Greene, G. (2002) Tracking California Seafloor Seeps with Bathymetry. Continental Shelf Research, 22, 2273-2290. http://dx.doi.org/10.1016/S0278-4343(02)00054-7

[9] McConnell, D., Gharib, J., Henderson, J., Danque, W.A., Digby, A. and Orange, D. (2008) Black Cold Seep-Hunting in Deepwater for Frontier Basins Prospectivity Assessment. AOA Geophysics, Inc., Houston.

[10] Naudts, L., Greinert, J., Artemov, Y., Beaubien, S.E., Borowski, C. and Batist, M. (2008) Anomalous Seafloor Backscatter Patterns in Methane Venting Areas, Dnepr Paleo-Delta, NW Black Sea, Marine. Geology, 251, 253-267. http://dx.doi.org/10.1016/j.margeo.2008.03.002

[11] Paull, C.K., Schlining, B., Ussler, W., Paduan, J.B., Caress, D. and Greene, H.G. (2005) Distribution of Chemosynthetic Biological Communities in Monterey Bay, California. Geology, 33, 85-88. http://dx.doi.org/10.1130/G20927.1

[12] Graham, R. and Pepper, A. (2009) Observations on Structures Associated with Mud Diapirism and Their Role in Petroleum Charging and Trapping Search and Discovery Article \#40419. http://www.searchanddiscovery.com/documents/2009/40419graham/ndx_graham.pdf

[13] MacAvoy, S.E., Fisher, C.R., Carney, R.S. and Macko, S.A. (2005) Nutritional Associations among Fauna at Hydrocarbon Seep Communities in the Gulf of Mexico. Marine Ecology Progress Series, 292, 51-60. http://dx.doi.org/10.3354/meps292051

[14] Zhang, Z., Digby, A., Gharib, J. and Chong, T.F. (2012) Analysis and Interpretation of High-Resolution Geophysical Data: Offshore Sarawak, South China Sea. Offshore Technology Conference, 30 April-3 May 2012, Houston, OTC 23155. http://dx.doi.org/10.4043/23155-ms

[15] Santodomingo, N., Reyes, J., Gracia, A., Martinez, A., Ojeda, G. and Garcia, C. (2007) Azooxanthellate Madracis Coral Communities off San Bernardo and Rosario Islands (Colombian Caribbean). Bulletin of Marine Science, 81, 273-287.

[16] Santodomingo, N., Reyes, J., Florez, P., Chacon Gomez, I.C., van Ofwegen, L.P. and Hoeksema, B.W. (2013) Diversity and Distribution of Azooxantellate Corals in the Colombian Caribbean. Marine Biology, 43, 7-22.

[17] Hernandez-Avila, I. (2014) Patterns of Deep-Water Coral Diversity in the Caribbean Basin and Adjacent Southern Waters: An Approach Based on Records from the R/V Pillsbury Expeditions. PLos ONE, 8, e92834. http://dx.doi.org/10.1371/journal.pone.0092834

[18] Aquabiosfera, A. (2015) Caracterización Ambiental del bloque Purple Angel, Caribe Colombiano. Aquabiosfera SAS para Anadarko Colombia Company Sucursal Colombia y Anadarko Petroleum Company, Bogotá D.C., 353.

[19] Groves, C.B., Valutis, L., Vosick, D., Neely, B., Wheaton, K., Touvaly, J. and Runnels, B. (2000) Designing a Geography of Hope: A Practitioner's Handbook for Eco-Regional Conservation Planning. 2nd Edition, The Nature Conservancy, I and II, 215. 